\title{
MRI versus clinical assessment in staging and response evaluation in locally advanced cervix cancer patients treated with concurrent chemo- radiation in a tertiary cancer center: a prospective study
}

\author{
Aravindh Sivanandan Anand*, Mintu Mathew Abraham, Vipin George Kuriakose
}

Department of Radiotherapy and Oncology, Government Medical College, Thiruvananthapuram, Kerala, India

Received: 19 December 2016

Accepted: 26 December 2016

\section{*Correspondence:}

Dr. Aravindh Sivanandan Anand,

E-mail: anandrt2006@yahoo.com

Copyright: () the author(s), publisher and licensee Medip Academy. This is an open-access article distributed under the terms of the Creative Commons Attribution Non-Commercial License, which permits unrestricted non-commercial use, distribution, and reproduction in any medium, provided the original work is properly cited.

\begin{abstract}
Background: Carcinoma cervix is staged most commonly with FIGO staging even though it has a number of pitfalls, for standardization of treatment and epidemiological purpose. The objectives of this prospective study are to evaluate the role of MRI in staging of locally advanced cervix cancer and correlate with the FIGO staging and to assess the role of MRI in evaluating treatment response.

Methods: 58 biopsy proved locally advanced carcinoma cervix patients who satisfied the inclusion and exclusion criteria from January 2014 to October 2015 were recruited. After the standard pretreatment evaluation including MRI abdomen and pelvis patients were started on concurrent chemo-radiation. Pelvic External beam radiation (EBRT) to a dose of $45 \mathrm{~Gy} / 23$ fractions for a period of 4.5 weeks with cisplatin $40 \mathrm{mg} / \mathrm{m} 2$ weekly once. Followed by intracavitary brachytherapy HDR weekly once 7Gy/fraction x 3 fractions. Treatment response assessed as per RECIST criteria. As a part of follow up, three monthly clinical evaluation and 4-6 months MRI evaluation were done.

Results: Agreement between MRI and clinical stage was evaluated by calculating the kappa value as the measure of agreement. The kappa value obtained was 0.18 which showed poor agreement between the two, while comparing clinical and MRI assessment with regard to treatment response, the kappa value obtained was 0.08 signifying poor agreement.

Conclusions: Correlation of FIGO and MRI staging reveals significant discordance between the two and on further evaluation it is seen that MRI staging correlates well with the local recurrence of the disease.
\end{abstract}

Keywords: Cancer cervix, FIGO stage, MRI, Treatment response

\section{INTRODUCTION}

Cervical carcinoma is currently the third most common gynaecological malignancy in the world, with data suggesting it to account about $9 \%$ of all newly detected female cancer malignancies and is the leading cause of mortality amongst women world over. ${ }^{1,2}$

In India, the age adjusted incidence rate of cervical carcinoma ranges from 19 to 44 per 1, 00,000 women in various cancer registries of Madras, Bangalore and Bombay. More women in India die from cervical cancer than in any other country. Cervical cancer kills around
72,000 women in India every year, more than $26 \%$ of the 275,000 deaths worldwide, says the report by the Cervical Cancer Free Coalition, The mortality rate in India is 15.2 , according to a chart CCFC compiled using data from the World Health Organization, the United Nations, the World Bank and the International Agency for Research on Cancer Globocan. ${ }^{3,4}$

Staging system recommended by International Federation of Gynecology and Obstetrics (FIGO) has been adopted worldwide for pretreatment staging purpose. The pitfall of FIGO staging however is the fact that it's based only on clinical assessment and has shown to be highly inter 
observer variable and inaccurate in the tumor extent assessment. $^{5}$ The revised FIGO staging that was implemented in 2009 recommends diagnostic imaging like CT and MRI, albeit not mandatory. ${ }^{6}$

Treatment approaches in Carcinoma Cervix are based on the clinical staging with Stage 1A-1B1 generally managed with surgery and 1B2- IVA generally with definitive radiotherapy where chemotherapy is used as a radio sensitizer. ${ }^{7-12}$ Henceforth a proper staging evaluation is extremely important to decide upon the primary treatment modality, especially in early stage disease and thus avoid the potential complications of a multimodality approach.

In patients with early-stage invasive cervical tumors (tumor size $<3 \mathrm{~cm}$, disease confined to the cervix) a multitude of studies have demonstrated the superiority of MRI (94\% accuracy and 95\% negative predictive value) in assessing parametrial invasion at the time of diagnosis. The fast spin-echo (FSE) T2-weighted image sequence helps to clearly delineate the parametrium and thus helping the treating clinician to decide upon the single modality treatment option. ${ }^{13-15}$

The accuracy of MRI over CT has also been validated in a large randomized phase 3 trial, where MRI had a higher sensitivity in disease detection, tumor size assessment and identifying uterine body involvement compared to CT scan. ${ }^{16,17}$

Even in advances stages, studies have shown that MRI can accurately rule out bladder and rectal invasion thus obviating the need for procedures like cystoscopy and procto-sigmoidoscopy which can be extremely distressing to the patients. ${ }^{18,19}$

This is an area where newer imaging modalities like MRI have indeed revolutionized the primary approach of management.

As far as response assessment, post therapy MRI has been validated to be better than PET at detecting residual disease, with a positive predictive value of $74 \%$ and negative predictive values as high as $100 \%$ with predictive value percentages in the forties for PET. [20]

Newer MR imaging sequences like perfusion - weighted (PW) and diffusion - weighted (DW) have demonstrated its ability to detect recurrence at its earliest, with DW images creating an image contrast based on the concept of water molecules being thermionically driven.

The response to treatment can be assessed in MRI using the Apparent Diffusion Coefficient values (ADC) pre and post treatment. ADC values are generally lower for malignant tissues when compared to normal tissues and hence the effectiveness of the therapy can be radiologically assessed by the improvement in the ADC values post treatment. This change in ADC is probably due to the alterations in cell membrane integrity and tumor cellularity post treatment. This observation had been successfully validated prospectively in a clinical setting, where ADC values were substantially high in complete responders compared to partial responders and patients with low pretreatment $\mathrm{ADC}$ values responded better to concurrent chemo radiation than those in ADC values on the higher side. ${ }^{21-23}$

Considering the fact that the data on MRI in clinical staging and response evaluation in locally advanced Carcinoma Cervix South Indian patients are sparse, we decided to prospectively conduct a study to compare MRI based assessment to conventional clinical assessment.

\section{Aims and objectives}

1. The primary objective of this prospective study is evaluate the role of MRI in staging of a newly diagnosed locally advanced cervix cancer and correlate with the FIGO staging in this context.

2. The secondary objective is to evaluate the role of MRI in assessing the treatment response and identify the residual disease.

\section{METHODS}

All carcinoma cervix patients who satisfied the inclusion and exclusion criteria and had reported to our institution for treatment from January 2014 to October 2015 were incorporated into the study. A total of 69 patients satisfied the enrolment criteria while 58 patients were finally available for evaluation after the planned treatment and study schedule.

\section{Inclusion criteria}

- Pathologically proven primary locally advanced cervical cancer with any histology suitable for primary treatment with chemo radiation with radical intent

- $\quad$ FIGO 2009, stage 1B2 to IVA

- Age 18 years or older

- Eastern Cooperative Oncology Group (ECOG) performance status 0-2

- Patients must have adequate Hematological and Renal function

- $\quad$ Patients willing for the study

\section{Exclusion criteria}

- Not willing for study

- Prior radiation or chemotherapy

- Patients not fit for intra-cavitary brachytherapy

- Metastatic disease.

- Pregnant or lactating

- Serious illness or medical condition that precludes the safe administration of the treatment like symptomatic congestive heart failure, unstable 
angina pectoris, cardiac arrhythmia, or psychiatric illness or social situations that would limit compliance with study requirements

\section{Methodology}

1. Patients fulfilling enrollment criteria are included in the study.

2. Written informed consent from each patient.

3. Detailed history and clinical examination prior to start of treatment as per the structured proforma

4. Pretreatment investigation include Biopsy from the primary lesion complete blood count, S. urea, S. creatinine, liver enzymes and bilirubin, HBs Ag, HCV, HIV, routine urine analysis, chest X-ray, MRI abdomen and pelvis will be done. CT pelvis in patients who have equivocal findings in MRI especially with regard to nodal involvement.

5. MRI studies were performed in 1.5-T machine. For this protocol, transverse and sagittal T1weighted spin-echo (SE) images and transverse T1-weighted fat-saturated images of the pelvis were obtained before and after contrast enhancement with gadolinium. Transverse and sagittal T2-weighted fast SE sequences of the pelvis were also obtained.

6. Patients started on concurrent chemo-radiation treatment. External beam pelvic radiation (EBRT) to a dose of $45 \mathrm{~Gy} / 23$ fractions over a period of 4.5 weeks with systemic chemotherapy with cisplatin $40 \mathrm{mg} / \mathrm{m} 2$ weekly once. Followed by intracavitary brachytherapy HDR weekly once $7 \mathrm{~Gy} /$ fraction x 3 fractions. Brachytherapy is started within one week of EBRT.

7. Clinical examination done during each visit for concurrent chemotherapy.

8. Treatment response assessed as per RECIST CRITERIA

9. Performance status evaluated by ECOG scale

10. Toxicity evaluation done with Common Terminology Criteria for Adverse Events v3.0 (CTCAE)

11. Clinical follow up done three monthly. Treatment response evaluation with MRI done every 4-6 months.

12. Patient was followed up monthly till the end of the study with clinical examinations.

\section{Data analysis}

Data analysis was done with the help of Excel 2010 and SSPS 16 statistical software.

\section{RESULTS}

A total of 69 locally advanced cervix cancer patients satisfying the inclusion criteria were enrolled for the study and 58 patients were available for assessment after completion of the planned treatment. The median age of the study group was 56 years. Vaginal bleeding was the most common presenting complaint and was seen in $68 \%$ of the patients followed by abnormal vaginal discharge, dyspareunia and growth in introitus.

Table 1: Baseline patient characteristics.

\begin{tabular}{|c|c|}
\hline Variable & $\begin{array}{l}\text { Description/ frequency } \\
(\%)\end{array}$ \\
\hline Median age & $56 \mathrm{yrs}$ \\
\hline $\begin{array}{l}\text { Main presenting } \\
\text { complaint }\end{array}$ & Bleeding per vaginum \\
\hline $\begin{array}{l}\text { Median duration of } \\
\text { symptoms }\end{array}$ & 5 months \\
\hline $\begin{array}{l}\text { Performance status } \\
\text { ECOG } 0 \\
\text { ECOG } 1 \\
\text { ECOG } 2\end{array}$ & $\begin{array}{l}20 \% \\
45 \% \\
35 \%\end{array}$ \\
\hline $\begin{array}{l}\text { FIGO stage } \\
\text { Stage } 1 \mathrm{~B} 2 \\
11 \mathrm{~A} 1 \\
11 \mathrm{~A} 2 \\
11 \mathrm{~B} \\
111 \mathrm{~A} \\
11 \mathrm{~B} \\
1 \mathrm{VA}\end{array}$ & $\begin{array}{r}3.6 \% \\
10.9 \% \\
18.8 \% \\
26.6 \% \\
18.8 \% \\
20.3 \% \\
1.6 \%\end{array}$ \\
\hline $\begin{array}{l}\text { Nodal involvement } \\
\text { No nodes involved } \\
\text { Paracervical } \\
\text { Internal iliac } \\
\text { External iliac } \\
\text { Common iliac }\end{array}$ & $\begin{array}{r}40.7 \% \\
15.6 \% \\
12.5 \% \\
25.0 \% \\
6.3 \%\end{array}$ \\
\hline $\begin{array}{l}\text { Histopathological } \\
\text { subtypes } \\
\text { Squamous cell carcinoma- } \\
\text { Non keratinizing } \\
\text { Squamous cell carcinoma- } \\
\text { Non keratinizing } \\
\text { Adenocarcinoma }\end{array}$ & $\begin{array}{r}71.9 \% \\
21.9 \% \\
6.3 \%\end{array}$ \\
\hline $\begin{array}{l}\text { MRI stage } \\
\text { Stage } 1 \mathrm{~B} 2 \\
11 \mathrm{~A} 1 \\
11 \mathrm{~A} 2 \\
11 \mathrm{~B} \\
111 \mathrm{~A} \\
111 \mathrm{~B} \\
1 \mathrm{VA}\end{array}$ & $\begin{array}{l}0 \\
4.7 \% \\
15.6 \% \\
39.1 \% \\
17.2 \% \\
23.4 \% \\
0\end{array}$ \\
\hline $\begin{array}{l}\text { Median number of } \\
\text { weekly chemotherapy } \\
\text { cycles }\end{array}$ & 4 \\
\hline $\begin{array}{l}\text { Radiation dermatitis } \\
\text { Grade } 0 \\
\text { Grade1 } \\
\text { Grade } 2 \\
\text { Grade3 }\end{array}$ & $\begin{array}{l}6.2 \% \\
10.8 \% \\
30.7 \% \\
52.3 \%\end{array}$ \\
\hline $\begin{array}{l}\text { GIT toxicity } \\
\text { Grade } 0 \\
\text { Grade } 1\end{array}$ & $\begin{array}{l}3 \% \\
46 \%\end{array}$ \\
\hline
\end{tabular}




\begin{tabular}{|ll|}
\hline Grade2 & $46 \%$ \\
Grade3 & $5 \%$ \\
\hline Genito urinary toxicity & \\
Grade 0 & 36.9 \\
Grade1 & 13.8 \\
Grade2 & 43.1 \\
\hline Median duration of & 64 days \\
treatment & \\
\hline Response rate & \\
MRI wise & 32 \\
Complete response & 23 \\
Partial response & 3 \\
Stable disease & 0 \\
progression & \\
\hline Response rate & \\
Clinical assessment & 46 \\
Complete response & 11 \\
Partial response & 1 \\
Stable disease & 0 \\
progression & \\
\hline
\end{tabular}

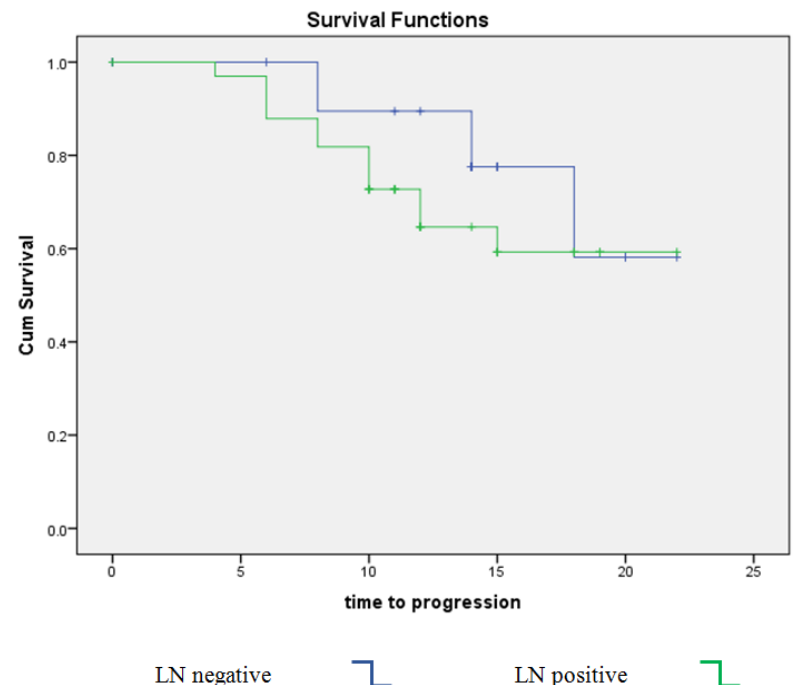

Figure 1: Kaplan-Meir survival curve - lymph node positive and negative.

The median duration of symptoms before seeking medical advice was 5 months. The average age of marriage among the study population was 18 years. $95.3 \%$ of the patients were multiparous. $72 \%$ of the patients had no history of a Pap smear done prior and remaining had history of one or two Pap smear done before this diagnosis. No contraceptive method was used in $47 \%$ of the patients while $40 \%$ had post-partum sterilization. $8 \%$ used barrier method of contraception while $5 \%$ gave history of oral contraceptive usage. $13 \%$ of patients had multiple sexual partners either for them or for spouse. All patients were initially staged clinically as per the FIGO staging. Most common stage in this set of patients was stage $11 \mathrm{~B}(26.6 \%)$ followed by stage $111 \mathrm{~B}$ and $111 \mathrm{~A}$ which was $20.3 \%$ and $18.8 \%$ respectively. MRI evaluation was done after FIGO staging and there was change in the FIGO stage after this evaluation. 8 patients were down staged while 12 patients were upstaged. In this study the agreement between MRI and clinical stage was evaluated by calculating the kappa value which is a measure of agreement. The kappa value obtained was 0.18 .

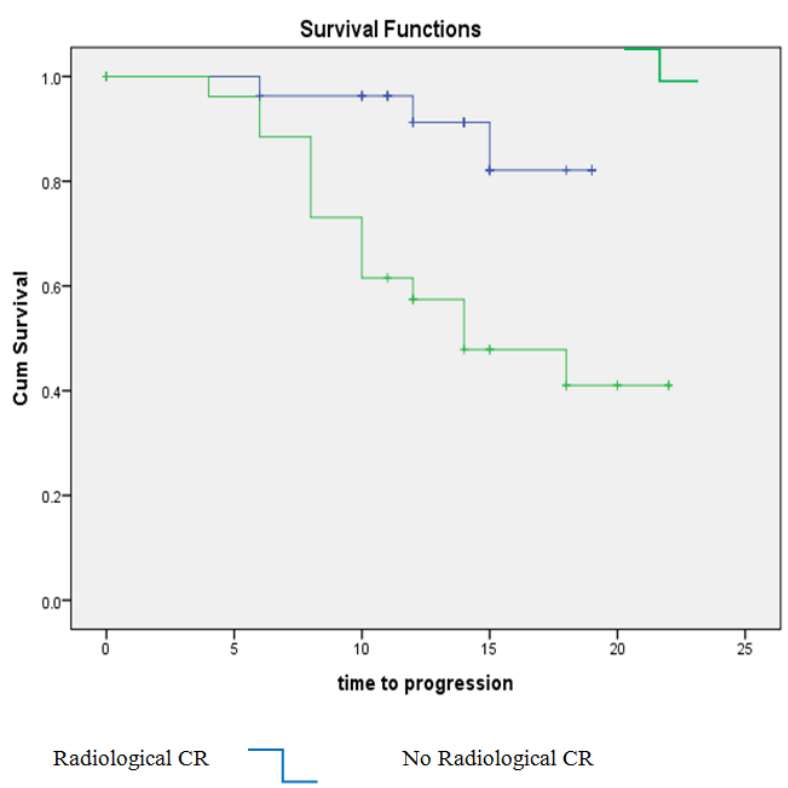

Figure 2: Kaplan-Meir curves - radiological complete response vs no radiological complete response.

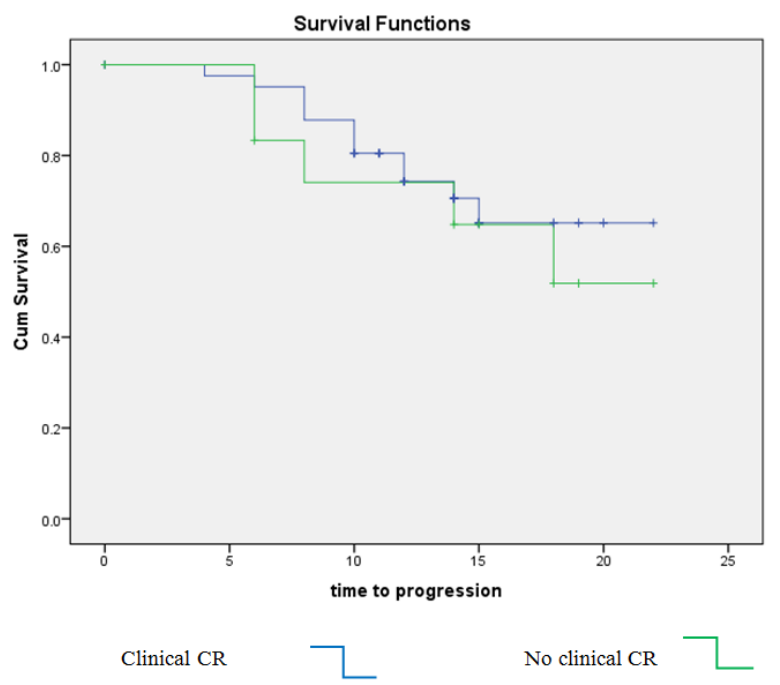

Figure 3: Kaplan-Meir curves - clinical complete response vs no clinical complete response.

The involvement of the loco regional lymph nodes were evaluated in MRI and is reported as the farthest lymph node involved as seen in MR. $40 \%$ patients were found to have no loco regional lymph node involvement.15.6\% patients had involvement up to the Para cervical lymph nodes only. Internal iliac was seen involved in $12.5 \%$, external iliac in $25 \%$ and common iliac in $6.3 \%$ of patients. The presence or absence of lymph node metastasis was compared to the progression free survival estimates. It was found that at the end of the study the median recurrence free survival was 16.8 months for 
patients without and 18.8 months for patients with lymph node involvement though the $\mathrm{p}$ value did not reach statistical significance $(p=0.164)$. The Kaplan-Meir survival plot was plotted for lymph node positive and negative patients as shown in Figure 1.

The major histological subtype was found to be Squamous cell carcinoma non keratinizing type (70\%). Keratinizing variety of squamous cell carcinoma was the $2^{\text {nd }}$ most common in $22 \%$ patients. Adenocarcinoma was seen in $6.3 \%$ patients. When squamous cell carcinoma and Adenocarcinoma subtype and treatment response rate was compared there was statistically significant difference $(\mathrm{p}=0.007)$ favouring squamous cell carcinoma. But the association was not found to be significant between pathological subtype and recurrence $(\mathrm{p}=0.167)$. No association could be found between the different subtypes of squamous cell carcinoma and the response or recurrence rate.

The median number of cycles of chemotherapy received by patients was 4 . The total number of patients who couldn't tolerate at least 4 cycles of chemotherapy were 6 (10\%). Chemotherapy was interrupted for 3 patients due to renal failure and 2 patients due to severe vomiting and in 1 patient due to electrolyte abnormalities. The highest recorded grade of radiation dermatitis in this group of patients was grade 3 which was observed in $52.3 \%$ followed by grade 2 and grade 3 in $30.7 \%$ and $10.8 \%$ respectively. Acute GIT toxicities of grade 1 or 2 were observed in 28 patients each. Grade 3 toxicity was seen in only 3 patients. Genito urinary toxicity was grade 0,1 , and 2 in $39 \%, 15 \%$ and $46 \%$ respectively.

The median duration of treatment (from $1^{\text {st }}$ day of radiation to last day of brachytherapy) was 64 days in this study. Breaks in radiation and delay in initiation of brachytherapy due to local reactions were observed to be the major cause of treatment delays in most patients. On evaluation of the survival estimates, it was found that patients who had not completed treatment in 64 days had a hazard ratio of 1.7 (95\% confidence interval .063-4.07 $\mathrm{p}=0.2$ ) for not attaining complete remission and the hazard ratio for recurrence was $1.2(95 \%$ confidence interval .43-4.33, $\mathrm{p}=0.6$ )

Of the 58 patients available for evaluation by RECIST criteria, 32 patients $(55.2 \%)$ had complete response, 22 patients had partial response and 3 patients had stable disease. Response rates were also assessed clinically at the time of MRI evaluation. It was found that $70 \%$ of patients had complete response clinically and $15 \%$ had a partial response and only 1 patient had stable disease. While comparing clinical response assessment to MRI assessment the kappa value obtained was 0.08 signifying poor agreement. One sample t-test comparing the differences in response assessment with 0 (complete agreement) revealed a mean difference of agreement of 0.28 with a significant p-value of 0.002 (Bland-Altman analysis).
At a median follow up of 12 months, 17 patients had developed recurrence. 10 patients in stage 11 and 7 patients in stage 111 developed recurrence that was staged by MRI. Out of the 17 patients who had recurrence, 10 had recurrence in the pelvis. 4 patients had abdominal recurrence, 1 patient each had recurrence $1^{\text {st }}$ detected as liver, lung, brain or others sites of metastasis.

The relation between response assessed by MRI and recurrence rate was evaluated .It was found that the hazard ratio of recurrence was 8.667 times between nonresponders and responders. The $\mathrm{p}$ value was found to be significant $(\mathrm{p}=0.001 .95 \%$ confidence interval 2.82 to 35.1). When assessing the response clinically, the hazard ratio was found to be 1.667 between non responders and responders but this was not statistically significant $(\mathrm{p}=0.438)$.

The mean recurrence free survival was 17.4 months $(95 \%$ confidence interval 15.338-19.175) .The Kaplan Meir survival analysis for recurrence free survival was $69.6 \%$ at the end of the study period. Median survival was not reached. Survival was separately plotted for patients who had achieved complete response (on MRI) vs. those who did not. Only $10.7 \%$ percent of the responders developed recurrence while $50 \%$ of the non-responders had recurrence (Figure 2).

When assessing the clinical response with the survival it was seen that the $72.1 \%$ of the responders and $61.5 \%$ of the non-responders had not had any recurrence (Figure $3)$.

\section{DISCUSSION}

The International Federation of Gynecology and Obstetrics (FIGO) staging system is the most widely used staging system for cancer cervix. Even though it has a lot of pitfalls it is being exhaustively used for standardization of epidemiologic and treatment results. ${ }^{24,25}$ FIGO staging is a clinical staging primarily based on the clinical examination findings performed with the patient under anesthesia. FIGO recommended investigations for this purpose include biopsy, dilatation and curettage, urine analysis, chest radiography, intravenous urography, barium enema studies, cystoscopy, and proctoscopy. Being a clinical staging there are interobserver variability in clinical examination. There are significant inaccuracies in the FIGO staging system, with a $24 \%-39 \%$ error rate in gynecologic examinations. ${ }^{24-27}$ Moreover, nodal disease status, uterine corpus involvement, extent of parametrium involvement, tumor volume which are prognostic factors, are not addressed in FIGO staging. ${ }^{28}$ Overall, the accuracy of MR imaging for depicting tumor size is $93 \%$, whereas that of clinical staging is less than $60 \% .^{29}$ Therefore, advanced imageological modalities like contrast enhanced (CECT), magnetic resonance (MR) imaging, PET CT scan are widely used as optimal for evaluation of the main prognostic factors and selection of therapeutic strategy. MRI scan well known for better soft 
tissue delineation and hence assessment of tumor volume and extent of disease. High spatial and contrast resolution of pelvic tissues and organs by MRI makes it a unique imaging modality and henceforth considered as a complimentary investigation by a lot. MRI is considered as the imaging modality of choice for local staging of cervical carcinoma. ${ }^{30}$ MRI is used in our institution for treatment strategies. There are discrepancies between tumors that are staged at clinical examination according to the FIGO staging system and those that are staged at surgery, with an error rate as high as $32 \%$ in patients with stage IB disease and $65 \%$ in patients with stage III disease ${ }^{31}$ Considering all these, we decided to conduct a prospective study to evaluate the role of MRI both in staging and treatment response assessment and then to correlate with clinical assessment by FIGO staging.

In this study we have prospectively evaluated 59 biopsy proved carcinoma of cervix that was considered for radical chemo radiation based on FIGO staging. Hence the study population consisted of basically locally advanced cervix cancer. Pretreatment MRI which was done in all these patients after FIGO staging showed disparities in staging. A total of 20 patients showed disparity between FIGO and MRI staging with majority i.e. 12 patients were upstaged and remaining down staged. The kappa factor of agreement between the two staging modalities was 0.18 , which shows the agreement is very poor. Hence in our study, there is significant disagreement in MRI staging and clinical staging. This is the same seen as per the literature search. Ozsarlak et al reported the overall accuracy of staging for clinical examination, CT, and MRI to be 47,53 , and 86 per cent respectively when compared with surgical findings. ${ }^{32,33}$ Hanncke et al in his study reported the sensitivity for the detection of advanced stage ( $\geq$ IIB) disease with the FIGO clinical staging, CT imaging, and MRI was 29\%, $42 \%$, and $53 \%$, respectively; the specificity was $99 \%$, $82 \%$, and $74 \%$, respectively; and the negative predictive value was $84 \%, 84 \%$, and $85 \%$, respectively. ${ }^{6}$

In the evaluation of local response, MRI allows both an assessment of the response to radiation treatment and difference between residual or recurrent tumor and radiation-induced fibrosis based on volume and signal intensity. ${ }^{34-36}$ In this study with regard to the treatment response assessment, there is very poor agreement with the clinical and MRI assessment. The kappa factor was 0.08 . The relation between response rates assessed by MRI and clinically was also assessed. With MRI the hazard ratio of recurrence was 8.667 between responders and non-responders. The $\mathrm{p}$ value was found to be significant $(\mathrm{p}=0.001 .95 \%$ confidence interval 2.82 to 35.1). When assessing the response clinically, the hazard ratio was found to be 1.667 between non responders and responders but this was not statistically significant $(\mathrm{p}=0.438)$.

In a study by Kaur et al MRI demonstrated a good correlation with clinical examination and transvaginal biopsy, and it correctly predicted residual tumor or recurrence in 27 of 28 patients with cervical cancer who were treated with primary RT. ${ }^{11}$ Similarly, in another study, MRI had a $90.4 \%$ accuracy rate in assessing tumor and parametrial spread regression after chemoradiation. ${ }^{37}$ Manfredi et al. reported that MRI was $78 \%$ accurate for evaluating the tumor response; however, in $22 \%$ of patients, benign conditions were not distinguishable from the residual tumor. Although dynamic MRI can improve specificity, early radiation change continues to pose a problem because it may show early enhancement. ${ }^{38}$ For this reason, MRI should be performed ideally at least 6 months after the completion of radiation therapy. In the case of a discordance between clinical and MRI findings, transvaginal or computed tomography-guided biopsy should be performed. In our study only $10 \%$ of the complete responder by MRI developed recurrence while more than $72 \%$ of complete responder by clinical assessment went in for recurrence.

Henceforth from our study and also from aforementioned other studies in literature MRI can be considered as an excellent imageological tool to evaluate treatment response while clinical assessment alone is inadequate. The significance of this happens when there is local residual disease post radiation treatment where an early surgical individualized decision is required.

A per the available literature there is no general consensus or guideline for the routine use of MRI after radiation treatment during the follow up period. Considering the lack of sufficient salvage treatment option in local relapse and also the efficacy of MRI in detection of residual disease the use of MRI in follow up period is to be considered. Our study being a prospective study has definitely thrown light into this topic when compared to the retrospective studies in literature but it has the limitation of not being a randomized study and there is no pathological correlation in residual disease detected clinically or MRI wise. Hence further prospective randomized studies mainly addressing the timing and frequency of MRI along with pathological correlation must be undertaken to reach at a consensus and to form a guideline.

\section{CONCLUSION}

Carcinoma cervix is a health problem especially in developing countries. FIGO staging is the most commonly used staging for carcinoma of cervix even though it has several pitfalls. MRI is an excellent tool in better defining the actual extent of the disease. Correlation of FIGO and MRI staging reveals that there is significant discordance between the two and on further evaluation it is seen that MRI staging correlates well with the local recurrence of the disease. It is further concluded that MRI is definitely a good imageology for assessment of treatment response and residual disease. Hence the need of incorporation of MRI in the standard follow up protocol merits top priority. Further prospective 
randomized studies must be conducted in this regard especially with clinical; MRI, functional imageology and histopathological correlation to better define the timing and frequency of post treatment MRI.

Funding: No funding sources

Conflict of interest: None declared

Ethical approval: The study was approved by the Institutional Ethics Committee

\section{REFERENCES}

1. Jemal A, Bray F, Center MM, Ferlay J, Ward E, Forman D. Global cancer statistics. CA Cancer J Clin. 2011;61(2):69-90.

2. World Cancer Research Fund International. 2012 September 22nd, 2015]. Available from: http://www.wcrf.org/int/cancer-factsfigures/worldwide-data.

3. National Cancer Registry Programme. Available from: www.ncrpindia.org _ALL_NCRP_REPORTS_HBCR_REPORT_2007_ 2011_ALL_CONTENT_ALL_PDF_Chapter 11 .

4. Cervical Cancer; Estimated Incidence, Mortality and Prevalence Worldwide in 2012. Available from: http://globocan.iarc.fr/old/FactSheets/cancers/cervixnew.asp.

5. Narayan K, McKenzie AF, Hicks RJ, Fisher R, Bernshaw D, Bau S. Relation between FIGO stage, primary tumor volume, and presence of lymph node metastases in cervical cancer patients referred for radiotherapy. Int J Gynecol Cancer. 2003;13:657-63.

6. Bipat S, Glas AS, van der Velden J, Zwinderman AH, Bossuyt PM, Stoker J. Computed tomography and magnetic resonance imaging in staging of uterine cervical carcinoma: a systematic review. Gynecol Oncol. 2003;91(1):59-66.

7. Eifel PJ, Winter K, Morris M, Levenback C, Grigsby $\mathrm{PW}$, Cooper J, et al. Pelvic irradiation with concurrent chemotherapy versus pelvic and paraaortic irradiation for high-risk cervical cancer: an update of radiation therapy oncology group trial (RTOG) 90-01. J Clin Oncol. 2004;22(5):872-80.

8. Morris M, Eifel PJ, Lu J, Grigsby PW, Levenback C, Stevens RE, et al. Pelvic radiation with concurrent chemotherapy compared with pelvic and para-aortic radiation for high-risk cervical cancer. N Engl J Med. 1999;340(15):1137-43.

9. Rose PG, Ali S, Watkins E, Thigpen JT, Deppe G, Clarke-Pearson DL, et al. Long-term follow-up of a randomized trial comparing concurrent single agent cisplatin, cisplatin-based combination chemotherapy, or hydroxyurea during pelvic irradiation for locally advanced cervical cancer: a Gynecologic Oncology Group Study. J Clin Oncol. 2007;25(19):2804-10.

10. Lanciano R, Calkins A, Bundy BN, Parham G, Lucci JA, 3rd, Moore DH, et al. Randomized comparison of weekly cisplatin or protracted venous infusion of fluorouracil in combination with pelvic radiation in advanced cervix cancer: a gynecologic oncology group study. J Clin Oncol. 2005;23(33):8289-95.

11. Holtz DO, Dunton C. Traditional management of invasive cervical cancer.Obstet Gynecol Clin North Am. 2002;29:645-657.

12. Rose PG, Bundy BN, Watkins EB, et al. Concurrent cisplatin-based radiotherapy and chemotherapy for locally advanced cervical cancer. N Engl J Med. 1999;340:1144-53

13. Sironi S, Villa G, Rossi S, Bocciolone L, Maggioni A, Sonzogni A, et al. Magnetic resonance imaging in the evaluation of parametrial invasion of carcinoma of the cervix uteri: optimization of the study protocol. La Radiologia medica. 2001;101(6):47784.

14. Iwata S, Joja I, Okuno K, Miyagi Y, Sakaguchi Y, Kudo T, et al. Cervical carcinoma with full-thickness stromal invasion: efficacy of dynamic MR imaging in the assessment of parametrial involvement. Radiation medicine. 2002;20(5):247-55.

15. Rizzo S, Calareso G, Maccagnoni S, Angileri SA, Landoni F, Raimondi S, et al. Pre-operative MR evaluation of features that indicate the need of adjuvant therapies in early stage cervical cancer patients. A single-centre experience. Euro $\mathrm{J}$ of Radiology. 2014;83(5):858-64.

16. Mitchell DG, Snyder B, Coakley F, Reinhold C, Thomas G, Amendola M, et al. Early invasive cervical cancer: tumor delineation by magnetic resonance imaging, computed tomography, and clinical examination, verified by pathologic results, in the ACRIN 6651/GOG 183 Intergroup Study. J Clin Oncol. 2006;24(36):5687-94.

17. Janus CL MD, Moore S. Staging of cervical carcinoma: Accuracy of magnetic resonance imaging and computed tomography. Clin Imaging. 1989.13:114.

18. Kim WY, Chang SJ, Chang KH, Yoo SC, Lee EJ, Ryu HS. Reliability of magnetic resonance imaging for bladder or rectum invasion in cervical cancer. The Journal of reproductive medicine. 2011;56(1112):485-90.

19. Rockall AG, Ghosh S, Alexander-Sefre F, Babar S, Younis MT, Naz S, et al. Can MRI rule out bladder and rectal invasion in cervical cancer to help select patients for limited EUA? Gynecologic oncology. 2006;101(2):244-9.

20. Vandecasteele K, Delrue L, Lambert B, Makar A, Lambein K, Denys $\mathrm{H}$, et al. Value of magnetic resonance and (1) (8)FDG PET-CT in predicting tumor response and resectability of primary locally advanced cervical cancer after treatment with intensity-modulated arc therapy: a prospective pathology-matched study. Int $\mathbf{J}$ Gynecol Cancer. 2012;22(4):630-7.

21. Kundu S, Chopra S, Verma A, Mahantshetty U, Engineer R, Shrivastava SK. Functional magnetic resonance imaging in cervical cancer: current evidence and future directions. J Cancer Res Ther. 2012;8(1):11-8. 
22. Kim HS, Kim CK, Park BK, Huh SJ, Kim B. Evaluation of therapeutic response to concurrent chemoradiotherapy in patients with cervical cancer using diffusion-weighted MR imaging. J Magn Reson Imaging. 2013;37(1):187-93.

23. Liu Y, Bai R, Sun H, Liu H, Zhao X, Li Y. Diffusion-weighted imaging in predicting and monitoring the response of uterine cervical cancer to combined chemoradiation. Clin Radiol. 2009;64(11):1067-74.

24. McCarthy S, Hricak $H$. The uterus and vagina. In: Higgins CB, Hricak H, Helms CA, eds. Magnetic resonance imaging of the body. 3rd ed. New York, NY: Lippincott-Raven, 1997;761-814.

25. Togashi K, Morikawa K, Kataoka ML, Konishi J. Cervical cancer. J Magn Reson Imaging 1998; 8:391397.

26. Reinhold C, Gallix BP, Ascher SM. Uterus and cervix. In: Semelka RC, Ascher SM, Reinhold C, eds. MRI of the abdomen and pelvis: a text atlas. New York, NY: Wiley-Liss. 1997; 585-660

27. Subak LL, Hricak H, Powell B, Azizi L, Stern JL. Cervical carcinoma: computed tomography and magnetic resonance imaging for preoperative staging. Obstet Gynecol 1995;86:43-50

28. Swift PS. Carcinoma of the uterine cervix. In: Liebel SA, Phillips TL, eds. Clinical radiation oncology. Philadelphia, Pa: Saunders, 1998:799-841.

29. Lagasse LD, Creasman WT, Shingleton HM, Ford JH, Blessing JA. Results and complications of operative staging in cervical cancer: experience of the Gynecologic Oncology Group. Gynecol Oncol 1980;9(1):90-8.

30. Balleyguier C, Sala E, Da Cunha T, Bergman A, Brkljacic B, Danza F, et al. Staging of uterine cervical cancer with MRI: guidelines of the European Society of Urogenital Radiology. Eur Radiol. 2011;21:1102-10.

31. Subak LL, Hricak H, Powell CB, Azizi L, Stern JL. Cervical carcinoma: computed tomography and magnetic resonance imaging for preoperative staging. Obstet Gynecol 1995;86(1):43-50.
32. Ozsarlak O, Tjalma W, Schepens E, Corthouts B, Op de Beeck B, Van Marck E, et al. The correlation of preoperative $\mathrm{CT}$, MR imaging, and clinical staging (FIGO) with histopathology findings in primary cervical carcinoma. Eur Radiol. 2003;13:2338-45.

33. Hancke K, Heilmann V, Straka P, Kreienberg R, Kurzeder C. Pretreatment staging of cervical cancer: is imaging better than palpation? Role of CT and MRI in preoperative staging of cervical cancer: single institution results for 255 patients Ann Surg Oncol. 2008;15:2856-61

34. Kaur H, Silverman PM, Iyer RB, Verschraegen CF, Eifel PJ, Charnsangavej C. Diagnosis, staging, and surveillance of cervical cancer. AJR. 2003;180:162131.

35. Flueckiger F, Ebner F, Poschauko H, Tamussino K, Einspieler R, Ranner G. Cervical cancer: serial MR imaging before and after primary RT- a 2 year follow-up study. Radiology. 1992;184:89-93.

36. Ebner F, Kressel HY, Mintz MC, et al. Tumor recurrence versus fibrosis in the female pelvis: differentian with MR imaging at $1.5 \mathrm{~T}$. Radiology. 1988;166:333-40.

37. Sironi S, Belloni C, Taccagni G, Del Maschio A. Invasive cervical carcinoma: MR imaging after preoperative chemotherapy. Radiology. 1991;190:719-22.

38. Kinkel K, Ariche M, Tardivon AA, et al. Differentiation between recurrent tumor and benign conditions after treatment of gynecologic pelvic carcinoma: value of dynamic contrast-enhanced subtraction MR imaging. Radiology. 1997;204:5563.

Cite this article as: Aravindh SA, Mintu MA, Vipin GK. MRI versus clinical assessment in staging and response evaluation in locally advanced cervix cancer patients treated with concurrent chemoradiation in a tertiary cancer center: a prospective study. Int J Reprod Contracept Obstet Gynecol 2017;6:392-9. 